\title{
Vincenzo Consolo i Alexis Eudald Solà: d'escriptor a traductor
}

\author{
Mercè Trullén
}

\section{Pròleg}

A finals del mes d'octubre de 2005, en una de les darreres visites de Vincenzo Consolo a Barcelona, quan sortíem de l'Institut Italià on s'havia presentat el volum n.10 de QUADERNS D'ITALIÀ dedicat a l'escriptor, el professor Giovanni Albertocchi em comunicà que també se'n faria la presentació a Girona i em va preguntar si hi voldria anar. Per a mi, anar a Girona sempre ha estat, és i serà un plaer i, evidentment li vaig dir que sí. A mitjans de gener em va trucar a casa i llavors la seva telefonada em va literalment desconcertar. No em comunicava que se'n faria la presentació per tal que hi anés com a espectadora sinó que jo hi intervindria. Em proposava que parlés de la relació de Consolo amb l'Alexis Eudald Solà, el seu traductor. Ja veieu el malentès. El meu ofici és més d'escoltar que de parlar. Per això, davant dels professors N. Messina i G. Albertocchi, coneixedors de l'obra de Consolo des del vessant universitari, què podia dir jo que en sóc només una fervent lectora?

En Giovanni em va dir que jo podia parlar de la relació que havien tingut Consolo amb l'Eudald, el meu marit. Amb tot, vaig pensar que potser podria dir alguna cosa interpretant el perquè de la traducció.

Per què un neoel.lenista que havia dedicat la seva vida acadèmica a l'ensenyament de la llengua i la literatura neogrega i a la traducció dels poetes grecs, que havia dedicat la seva vida a la difusió de la cultura catalana a Grècia i de la cultura grega a Catalunya, ell, l'Alexis Eudald Solà es posava a traduir un llibre de l'italià? Aquesta pregunta la deixo a l'aire.

\section{Capítol I}

Un matí a Foixà l'Eudald em llegeix una pàgina escrita en una llibreta d'espiral amb tinta de color sèpia. -Què te’n sembla? Sonava molt bé, però li vaig dir: - No te'n sortiràs. Havia començat a traduir El somrís del mariner inconegut. Una pàgina, només una pàgina. Feia poc que havíem tornat de Sicília -D'això fa més de 20 anys! Tots dos l'havíem llegit. Jo no n'havia entès un 
borrall malgrat que havia passat per les aules d'italià de Barcelona, Siena i Urbino! - Vull que quedi clar que n'eximeixo de tota culpa al magnífic professorat que vaig tenir! —Ell n'havia captat l'essència profunda. I el mariner va ser un repte que es va anar marcant des d'aquell llunyà 1984 fins al 2001. Un repte amb un gran plaer implícit. Jo vaig haver de fer-ne moltes lectures per anarlo entenent. Els diversos registres de llenguatge em depassaven. I quina riquesa de lèxic!

Després d'aquell matí a Foixà, varen ser moltes tardes a Barcelona que, en tornar a casa, entrava al despatx a dir-li hola i, sense tenir ni temps de treure’m l'abric, em deia: —Seu i escolta. I em llegia mitja pàgina traduïda. — Què te'n sembla, me'n surto?- Realment, quina comprensió del text i quina manera de trobar-li la correspondència en la nostra llengua!

- Ah, tot això si ho puc fer és gràcies al Moll, em deia sovint. (Es referia evidentment al diccionari Alcover-Moll). Aquest «me'n surto» va passar a formar part del nostre «vocabulari familiar».

\section{Capítol II}

Una tarda de juny de 2004 a Girona s'inaugurava una exposició a la Fontana d'Or que duia per títol: Empúries, un viatge de retorn. Aquesta mostra - de la qual se'n va fer un magnífic catàleg que va ser traduït al grec pel professor Francesc Morfulleda - després viatjà a Nicòsia, Atenes i Tessalònica. En aquesta exposició que va ser molt visitada, es mostraven uns gravats impressionants que l'artista Joan Barbarà havia realitzat després d'un viatge a Grècia amb l'Eudald. També s'hi exposava un llibre en edició de bibliòfil que varen editar en 1992 i que havien realitzat tos dos amb una sintonia incommensurable. Els gravats de J. Barbarà, el text de l'Eudald. El títol: Empúries, inici d'un retorn. El viatge de retorn des de l'Empúries fundada pels grecs fins a les envistes de Focea passant per tots els indrets de la nostra Mediterrània on han quedat les petjades de l'alta cultura. El text comença així:

Vista des de la carena que, a ponent, fa de teló de fons del castell dels senyors de Foixà, just allí on els territoris dels comtes d'Empúries termenegen amb les possessions de la mitra de Girona, la terra de l'alt i del baix Empordà s'estén, arran de mar, en una àmplia visió que, de pol a pol, s'inicia al cap Norfeu i, tot seguint encara més enllà de la vila blanca i encimbellada de Begur i del far de Sant Sebastià, arriba a la vall del riu d'Aro i gairebé als primers contraforts de la Selva.

Aquest viatge de retorn s'atura en un capítol que duu per títol: Alle speranze dell'isole felici. Sicília, les Eòlies. Terra i mar de Consolo i del mariner inconegut. 


\section{Capítol III}

Amb mi aprengueres de la mar, jo amb tu el sentit de cada far.

Aquests dos versos de la impressionant cançó Ens veiem a Folégandros, que Lluís Llach va escriure i compondre en memòria del seu amic Eudald Solà, tenen tot el sentit del llibre abans esmentat. En les nits de navegació per la Mediterrània foren moltes les vegades que li va dir a l'Eudald que havia d'escriure un llibre sobre el viatge.

En el fons, Empúries, inici d'un retorn surt d'aquests viatges per mar. De les terres catalanes fins a Grècia. En el llibre, quan l'Eudald parla d'ell mateix, escriu el mariner. I és cert. El capità era el Lluís i ell, el mariner.

I tot sortia de les converses en les llargues hores de travessia on, evidentment, no es podia deixar de parlar de l'obra capital de Nicolau d'Olwer:

\section{Capítol IV}

\section{El pont de la mar blava}

El pont que tant ens ha unit a nosaltres a través de la Història i de la Literatura. I ens ha unit a nosaltres els amics, com tan bé ho diu el gran mestre Joan Bastardas a través de "els camins de la mar», aquests camins, aquest pont entre Sicília i Catalunya.

El pont de la mar blava de Lluís Nicolau d'Olwer ha estat objecte de lectura del nostre escriptor Vincenzo Consolo i de la nostra comuna amiga siciliana Marina Scarlata, la gran professora d'història medieval. Quantes vegades havíem parlat de traduir-lo a l'italià. I el projecte encara és viu.

El pont de les amistats sicilianes: a partir de la professora neohel.lenista Renata Lavagnini, gran especialista en Kavafis, hi ha la coneixença amb la professora Marina Scarlata que tan i tan sovint havia vingut a treballar a l'Arxiu de la Corona d'Aragó i fou a casa seva, a Palerm, on es conegueren Solà i Consolo la primavera de 1984 .

Els punts en comú ja us podeu imaginar que varen ser molts. Converses interminables. Coincidències a tots nivells. S'entenien perfectament. Quina riquesa per part meva poder conviure amb aquestes persones.

\section{Capítol V}

\section{El retorn}

Després de l'acte a l'Institut Italià del qual parlàvem a l'inici, ens vam dirigir a la casa on havia viscut Nicolau d'Olwer. (Sí, el destí va voler que l'Eudald i jo anéssim a viure al mateix pis on havia viscut Nicolau.) Aquell vespre vàrem compartir taula amb la Caterina i el Vincenzo Consolo els amics catalans: Lloveras, Malaret, Morfulleda, Rizza, Susanna i Viladot. L'endemà la Caterina, el Vincenzo i jo mateixa empreníem el viatge cap a Itàlia. Ells dos cap a Milà i 
jo cap a Palerm. El meu viatge no era pel llibre del mariner, sinó per parlar amb la professora Lavagnini de l'edició del darrer llibre de Kavafis que havia deixat enllestit l'Eudald.

Aquells dies m'estava a casa de la Marina Scarlata i, amb ella i l'Antonio, es va acomplir el meu desig. Jo havia estat a Sicília quatre o cinc vegades, però hi havia un lloc que em mancava. Només l'havia vist passant-hi amb el tren. El Mar, el poble, la gran roca, la catedral. Quantes vegades me n'havia parlat l'Eudald. El desig era Cefalú.

Va ser per mi impressionant la visita a la casa d'Enrico Piraino, passar per les sales fins a arribar davant del retrat d'Antonello de Messina: Retrat d'Inconegut. Els encarregats del museu Mandralisca em van ensenyar la col-lecció de malacologia, l'esplèndida biblioteca. Allí s'hi respirava tot el viatge: Consolo, el mariner, l'Eudald, tots els anys que havia passat amb ell. Els racons del cor ben plens. L'escrit que va fer Vinzenzo Consolo i que de manera tan bonica va editar el doctor Enzo Crea a Roma quan l'Eudald va morir, l'acolliment a la casa de Milà per rellegir i com diu Consolo «llimar» el mariner, la darrera trobada a Barcelona. I ara, Girona.

El viatge començava a Foixà, en terres gironines i avui tornem en terres gironines per parlar de Consolo.

De fet, en El somris del mariner inconegut hi ha la simbologia del cargol, tot passa en espiral. Però jo avui he traçat un cercle. Havia de parlar de la relació entre Consolo i Solà; a través d'aquest recorregut potser he fet entendre perquè l'Eudald es va enamorar de l'obra i de les obres de Consolo. L'admirava com escriptor i com a persona.

Sicília, la Magna Gràcia. El viatge de retorn. Ítaca.

Com Ulisses va fer el llarg viatge, així també Consolo va fer el llarg viatge per escriure el mariner i l'Eudald el llarg viatge per traduir-lo. Ítaca, la nostra estimada Ítaca, terra del retorn. L'Eudald traductor de poesia, tradueix Consolo. El Mariner és un gran text poètic.

Després d'aquest viatge, potser trobem la resposta a la pregunta que formulava a l'inici.

Tots dos s'han estimat la pròpia terra i la pròpia llengua, tots dos es van trobar.

Girona, 13 de març de 2006

\section{Les fonts d'on brollen els textos}

Consolo, Vincenzo (2006). El somrís del mariner inconegut. Traducció d'Alexis Eudald Solà. Barcelona: Proa.

BarbarÀ, Joan; SolÀ, Alexis Eudald (1992). Empúries, inici d'un retorn. Edició de bibliòfil. Barcelona.

Empúries, un viatge de retorn (2004). Catàleg de l'exposició. Inclou la reproducció a escala reduïda del llibre Empúries, inici d'un retorn. Girona: Fundació Caixa de Girona. 
KaVAfIS, Konstandinos P. Una simfonia inacabada. Trenta-quatre poemes en esbós. Traducció i notes d'Alexis Eudald Solà. Barcelona: Viena Edicions (en premsa).

Alcover, Antoni M.; Moll, Francesc de B. Diccionari Català-Valencià-Balear. Palma de Mallorca:1968. Barcelona:1969.

LLACH, Lluís (2004). Ens veiem a Folégandros. Discografia: Jocs: BMG 2002 i Poetes. Edicions de l'Empordà BMG.

GinZBURG, Natalia (1989). Vocabulari familiar. Traducció de Mercè Trullén. Barcelona: Proa.

Lluís NiCOLAu D'OlWer (1928). El pont de la mar blava. Barcelona: Llibreria Catalònia.

Epileg

El 12 de Febrer de 2007 tenia lloc a la Pedrera, seu de la Fundació Caixa de Catalunya, l'acte de presentació de El somrís del mariner inconegut amb la presència de Vincenzo Consolo i amb la participació de Nicolò Messina, Àlex Susanna i Josep Maria Flotats. 